\title{
OPEN Pelvic floor dysfunction one year after first childbirth in relation to perineal tear severity
}

\begin{abstract}
Malin Huber $^{1 \bowtie}$, Ellen Malers ${ }^{2}$ \& Katarina Tunón ${ }^{1}$
The aims of this study were to evaluate pelvic floor dysfunction symptoms one year after delivery and investigate whether adverse functional outcomes after childbirth were related to the degree of perineal injury. A prospective cohort of 776 primiparas were included. Self-reported pelvic floor function data were obtained using a web-based questionnaire. Women with no/first-degree injuries, second-degree injuries, third-/fourth-degree injuries (obstetric anal sphincter injury, OASI) and cesarean section were compared. A total of 511 women (66\%) responded. Second-degree tears were a risk factor for stress incontinence (aOR $2.6(95 \% \mathrm{Cl} 1.3-5.1)$ ). Cesarean section was protective against stress incontinence (aOR $0.2(95 \% \mathrm{Cl} 0.1-0.9)$ ). OASI was a risk factor for urge incontinence (aOR 4.8 (95\% Cl 1.6-15)), prolapse (aOR 7.7 (95\% Cl 2.1-29)) and pelvic pain (OR $3.3(95 \% \mathrm{Cl} 1.1-10)$ ). Dyspareunia was reported by $38 \%$ of women, $63 \%$ of women in the OASI group (aOR $3.1(95 \% \mathrm{Cl}$ 1.1-9.0)). Women with OASI reported that the injury affected daily life (OR 18 (95\% CI 5.1-59)). Pelvic floor dysfunction is common after childbirth, even in women with moderate injury. Women with OASI had significantly higher risks of symptoms of prolapse, urge urinary incontinence, pain, dyspareunia and impacts on daily life.
\end{abstract}

Approximately $80 \%$ of primiparas suffer from perineal laceration. An estimated $40-50 \%$ of lacerations involve the perineal muscles, and up to $7 \%$ of these women suffer from severe obstetric anal sphincter injury (OASI) $)^{1,2}$. The prevalence rates of minor (first-degree) and muscular (second-degree) lacerations are estimated according to clinical experience, and these data are not always recorded in patient charts or registers. OASI is the most common cause of anal incontinence among women. Grade two and OASI can lead to perineal pain and dyspareunia and increase the risk of concomitant pelvic floor disorders ${ }^{3}$. The association between previous birth-related pelvic floor muscle trauma and future signs of pelvic organ prolapse has been shown in long-term follow-up studies ${ }^{4}$. The odds of fecal or urinary incontinence four years after delivery are markedly higher among women who experience pelvic disorder symptoms in the first year after birth ${ }^{5}$. Perineal trauma has been shown to relate to the frequency and severity of postpartum dyspareunia ${ }^{6}$.

Research has primarily focused on the risk factors and complications of OASI, although vast areas in the field remain unexplored ${ }^{7}$. There is also a lack of knowledge about the extent of short-term complications following moderate spontaneous or iatrogenic injuries to the perineal muscles.

The aims of this study were to evaluate symptoms of prolapse, urinary and anal incontinence, and perineal pain as well as sexual function one year after birth and investigate whether adverse functional outcomes were related to the degree of perineal injury. We hypothesized that the prevalence of symptoms of postpartum pelvic floor dysfunction would be related to the degree of perineal trauma.

\section{Results}

A flowchart of participant retention in the study is presented in Fig. 1. The one-year follow-up questionnaire was distributed to 776 women, and 511 participants completed the questionnaire, accounting for a response rate of $66 \%$. Of these participants, $74(14.2 \%)$ were excluded from the analysis of symptoms due to de novo pregnancy, and $12(2.3 \%)$ datasets were illegible/incomplete. Table 1 shows the descriptive statistics of the responders and nonresponders. There were no differences between the women who participated in the follow-up and the nonresponders regarding rates of perineal trauma. The respondents were older, and among them, the vacuum delivery rate was higher. Epidural use was more common among nonresponders than among responders (Table 1).

${ }^{1}$ Department of Clinical Sciences, Obstetrics and Gynecology, Umeå University, 90187 Umeå, Sweden. ${ }^{2}$ Department of Clinical Sciences, Obstetrics and Gynecology, Unit of Obstetrics and Gynecology-Östersund, Umeå University, Umeå, Sweden. ${ }^{\circledR}$ email: malin.huber@umu.se 


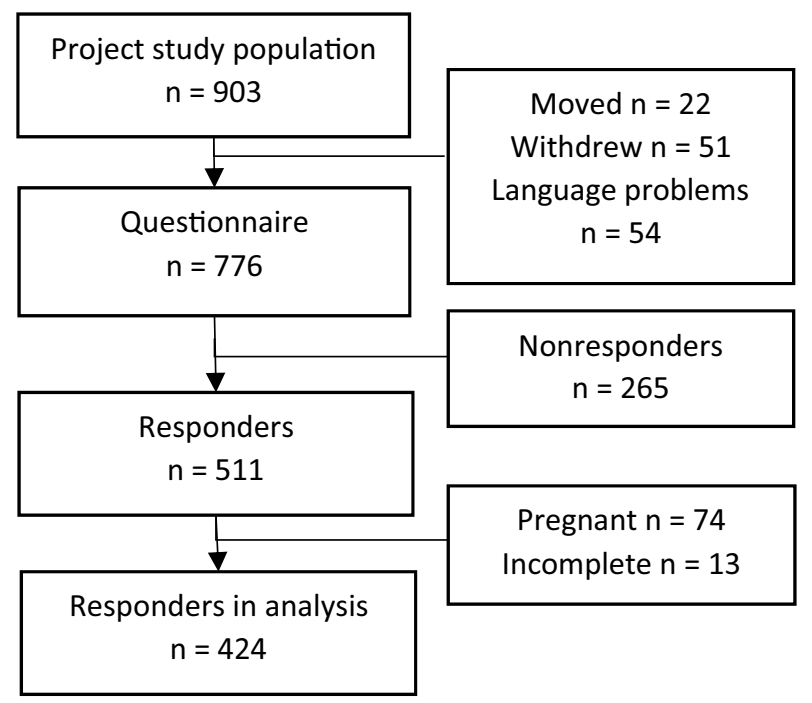

Figure 1. Flow chart of the study population.

\begin{tabular}{|c|c|c|c|}
\hline Characteristics & $\begin{array}{l}\text { Responders } \\
\mathrm{n}=511\end{array}$ & $\begin{array}{l}\text { Nonresponders } \\
n=265\end{array}$ & $p$ value \\
\hline \multicolumn{4}{|l|}{ Maternal factors } \\
\hline Maternal age (years), mean & $30.3( \pm 4.5)$ & $28.6( \pm 5.0)$ & $<0.001$ \\
\hline Body mass index $\left(\mathrm{kg} / \mathrm{m}^{2}\right)$, mean & $25.0( \pm 4.6)$ & $24.7( \pm 4.2)$ & 0.323 \\
\hline Smoking & $2(0.4)$ & $4(1.5)$ & na \\
\hline \multicolumn{4}{|l|}{ Fetal factors } \\
\hline Birthweight (g), mean & $3459( \pm 564)$ & $3426( \pm 528)$ & 0.428 \\
\hline Head circumference $(\mathrm{cm})$, mean & $34.8( \pm 2.3)$ & $34.7( \pm 1.5)$ & 0.309 \\
\hline pH umbilical artery, mean & $7.27( \pm 0.08)$ & $7.26( \pm 0.08)$ & na \\
\hline \multicolumn{4}{|l|}{ Presentation } \\
\hline Occiput anterior & $448(87.7)$ & $235(88.7)$ & 0.682 \\
\hline Occiput posterior & $26(5.1)$ & $9(3.4)$ & 0.282 \\
\hline Breech, $\mathrm{n}$ & $19(3.7)$ & $10(3.8)$ & na \\
\hline \multicolumn{4}{|l|}{ Obstetric factors } \\
\hline \multicolumn{4}{|l|}{ Labor onset } \\
\hline Spontaneous & $390(76.3)$ & $197(74.3)$ & 0.542 \\
\hline Induction & $95(18.6)$ & $56(21.1)$ & 0.396 \\
\hline Elective cesarean & $26(5.1)$ & $12(4.5)$ & 0.732 \\
\hline \multicolumn{4}{|l|}{ Labor outcomes } \\
\hline Length of active secondary state ( $\mathrm{min}$ ) & 32 & 32 & na \\
\hline Oxytocin & $325(63.6)$ & $181(68.3)$ & 0.217 \\
\hline Epidural & $304(59.5)$ & $187(70.6)$ & 0.002 \\
\hline Vacuum extraction & $61(11.9)$ & $15(5.7)$ & 0.005 \\
\hline Episiotomy & $101(19.8)$ & $47(17.7)$ & 0.495 \\
\hline Cesarean section & $69(13.5)$ & $43(16.2)$ & 0.306 \\
\hline \multicolumn{4}{|l|}{ Perineal trauma } \\
\hline No/1st-degree injury & $216(42.3)$ & $117(44.2)$ & 0.616 \\
\hline 2nd-degree injury, n & $201(39.3)$ & $97(36.6)$ & 0.458 \\
\hline 3rd-/4th-degree injury & $25(5.0)$ & $8(3.1)$ & 0.22 \\
\hline
\end{tabular}

Table 1. Demographic and obstetric characteristics of the study population. Data are presented as the mean \pm standard deviation $(\mathrm{SD})$ or $\mathrm{n}(\%){ }^{\star}{ }^{\star} \mathrm{na}=$ not analyzed. 


\begin{tabular}{|c|c|c|c|c|c|}
\hline Characteristics & $\begin{array}{l}\text { No injury/1st degree } \\
n=176(41.5)\end{array}$ & $\begin{array}{l}\text { 2nd degree } n=175 \\
\text { (41.3) }\end{array}$ & OASIS $n=19$ & $\begin{array}{l}\text { Cesarean section } \mathrm{n}=54 \\
(12.7)\end{array}$ & $p$ value \\
\hline \multicolumn{6}{|l|}{ Maternal factors } \\
\hline Maternal age (years) & $30( \pm 4.4)$ & $30( \pm 4.6)$ & $31( \pm 3.6)$ & $32( \pm 4.8)$ & 0.072 \\
\hline Body mass index $\left(\mathrm{kg} / \mathrm{m}^{2}\right)$ & $25( \pm 4.1)$ & $25( \pm 4.4)$ & $26( \pm 4.2)$ & $26( \pm 5.3)$ & 0.177 \\
\hline \multicolumn{6}{|c|}{ Fetal factors } \\
\hline Birthweight (g) & $3415( \pm 503)$ & $3513( \pm 494)$ & $3786( \pm 617)$ & $3349( \pm 802)$ & 0.009 \\
\hline Head circumf. $(\mathrm{cm})$ & $34.7( \pm 2.1)$ & $34.8( \pm 2.7)$ & $35.0( \pm 1.5)$ & $35.1( \pm 2.2)$ & 0.758 \\
\hline Ph Umbilical artery & $7.27( \pm 0.08))$ & $7.27( \pm 0.08)$ & $7.26( \pm 0.07)$ & $7.24( \pm 0.07)$ & 0.103 \\
\hline \multicolumn{6}{|l|}{ Presentation } \\
\hline Occiput anterior & $170(97.1)$ & $165(93.8)$ & $16(84.2)$ & $21(38.9)$ & $<0.001$ \\
\hline Occiput posterior & $4(2.3)$ & $11(6.3)$ & $3(15.8)$ & $5(9.3)$ & 0.018 \\
\hline Other & $2(0.01)$ & 0 & 0 & $15(27.8)$ & $\mathrm{na}^{*}$ \\
\hline \multicolumn{6}{|l|}{ Obstetric factors } \\
\hline Gestational age (days) & $278( \pm 14)$ & $279( \pm 11)$ & $281( \pm 8)$ & $275( \pm 22)$ & 0.311 \\
\hline \multicolumn{6}{|l|}{ Labor onset } \\
\hline Spontaneous & $146(83.4)$ & $148(84.1)$ & $15(78.9)$ & $20(37.0)$ & $<0.001$ \\
\hline Induction & $29(16.6)$ & $28(15.9)$ & $4(21.1)$ & $15(27.8)$ & 0.221 \\
\hline Elective cesarean section & & & & $19(35.2)$ & \\
\hline \multicolumn{6}{|l|}{ Labor outcomes } \\
\hline $\begin{array}{l}\text { Active secondary state } \\
\text { (min) }\end{array}$ & 32 & 41 & 41 & $\mathrm{na}^{*}$ & 0.002 \\
\hline Oxytocin & $107(61.5)$ & $123(69.9)$ & $13(68.4)$ & $29(53.7)$ & 0.123 \\
\hline Epidural & $109(62.3)$ & $105(59.7)$ & $11(57.9)$ & $25(46.3)$ & 0.219 \\
\hline Vacuum extraction & $11(6.3)$ & $34(19.3)$ & $3(12.0)$ & 0 & 0.001 \\
\hline Episiotomy & 0 & $80(45.5)$ & $5(26.3)$ & 0 & $\mathrm{na}^{*}$ \\
\hline
\end{tabular}

Table 2. Demographic and obstetric characteristics of analyzed responders in the three different groups of perineal trauma and cesarean section. Data are the mean $\pm \mathrm{SD}$ or $\mathrm{n}(\%) .{ }^{*}$ na $=$ not analyzed.

The demographic and obstetric characteristics of the responders in the three different perineal trauma groups and the cesarean section group are presented and compared in Table 2. There were no differences among the three injury groups regarding maternal age, body mass index, infant head circumference, gestational age at delivery, induction rate, labor augmentation or epidural use. The duration of the active secondary stage of labor was significantly longer in patients with second-degree injuries than in those with an intact perineum or first-degree injuries. There was a significant difference in infant birthweight between patients with no or minor perineal trauma and OASI, with the highest infant birthweight among women affected by OASI. Occiput posterior presentation was more common in the OASI group than in the other groups, but the difference was not significant after post hoc testing.

Obstetrical vacuum extraction was most common in those with second-degree injuries. Mediolateral episiotomy was performed in $20.0 \%(85 / 424)$ of all women, resulting in iatrogenic injury in $45.5 \%(80 / 175)$ of the women with second-degree tears. Among women with second-degree lacerations, episiotomy was more common in deliveries by vacuum extraction $(73.5 \% 25 / 34)$ than in spontaneous deliveries $(38.7 \%, 55 / 142, \mathrm{p}<0.001)$. In the OASI group, the episiotomy rate was $26.3 \%$, and none of the deliveries were vacuum assisted. There were no forceps deliveries.

Symptoms of prolapse were reported in $8.3 \%$ of the primiparas one year after delivery. OASI was a risk factor for developing symptoms of prolapse (aOR 7.7, Table 3). In total, $6.2 \%$ of the patients had to insert a finger in the vagina to assist in emptying their bowels.

Urinary stress incontinence was present in $31.0 \%$ of women, and $18.0 \%$ suffered from urge incontinence. Second-degree trauma was a risk factor for stress incontinence (aOR 2.6, Table 3), and giving birth by cesarean section was protective against stress incontinence (aOR 0.2, Table 3). The risk for urge (aOR 4.7, Table 3 ) incontinence was elevated in the group with the largest injuries. An impact on lifestyle was reported in $12.1 \%$ of the women with urinary incontinence, and in women with OASI, the risk of urinary incontinence that affected their lifestyle was significantly elevated (Table 3 ).

Anal incontinence was experienced by $13.9 \%$ of women. Severe incontinence with leakage of solid stool was reported after only vaginal delivery. The severity of the symptoms was more prominent among women in the OASI group, who also had an increased risk of anal incontinence affecting their lifestyle, than among women in the other groups (OR 23, Table 3).

Most of the women were sexually active, although $9.7 \%$ of the women had not resumed sexual relations. Four women chose not to answer the question. Dyspareunia was experienced by a large proportion, accounting for $38.3 \%$ of the women who were sexually active. The rate of dyspareunia ranged from $31.3-41.4 \%$ in the groups with first/second-degree injuries and cesarean section and reached $62.5 \%$ in the group with OASI. The risk of 


\begin{tabular}{|c|c|c|c|c|}
\hline Outcome measure & $\begin{array}{l}\text { No injury/1st degree } \\
n=175(41.2 \%)\end{array}$ & $\begin{array}{l}\text { 2nd degree } \\
n=176(41.6 \%)\end{array}$ & $\begin{array}{l}\text { OASIS } \\
n=19 \\
(4.5 \%)\end{array}$ & $\begin{array}{l}\text { Cesarean section } \\
n=54(12.7 \%)\end{array}$ \\
\hline \multicolumn{5}{|l|}{ Adjusted ORa for symptoms of } \\
\hline \multicolumn{5}{|l|}{ Prolapse } \\
\hline Sense of something bulging & Reference & $1.4(0.6-3.3)$ & $7.7(2.1-29)$ & $0.5(0.1-2.0)$ \\
\hline Help empty bowel & Reference & $0.7(0.3-1.7)$ & $1.4(0.2-8.9)$ & $1.0(0.3-3.4)$ \\
\hline \multicolumn{5}{|l|}{ Urinary incontinence } \\
\hline Stress incontinence & Reference & $2.6(1.3-5.1)$ & $2.6(0.7-10)$ & $0.2(0.1-0.9)$ \\
\hline Urge incontinence & Reference & $1.2(0.7-2.2)$ & $4.8(1.6-15)$ & $0.6(0.2-1.4)$ \\
\hline \multicolumn{5}{|l|}{ Anal incontinence } \\
\hline Any anal incontinence & Reference & $0.9(0.5-1.7)$ & $2.8(0.9-9.3)$ & $0.3(0.1-1.1)$ \\
\hline \multicolumn{5}{|l|}{ Crude OR for } \\
\hline \multicolumn{5}{|l|}{ Sexual function } \\
\hline Pain during intercourse & Reference & $1.3(0.8-2.1)$ & $3.1(1.1-9.0)$ & $0.7(0.4-1.3)$ \\
\hline \multicolumn{5}{|l|}{ Other } \\
\hline Pain (not intercourse) & Reference & $1.4(0.7-2.7)$ & $3.3(1.1-10)$ & $0.6(0.2-1.7)$ \\
\hline Injury affects daily life & Reference & $1.2(0.4-3.6)$ & $18(5.1-59)$ & na \\
\hline Urine incontinence that affects lifestyle & Reference & $1.8(0.9-3.5)$ & $4.6(1.5-14)$ & $0.3(0.1-1.1)$ \\
\hline Anal incontinence that affects lifestyle & Reference & $2.9(0.5-17)$ & $23(2.5-213)$ & na \\
\hline Satisfied with suture of injury & Reference & $0.5(0.3-0.9)$ & $0.3(0.1-0.8)$ & na \\
\hline
\end{tabular}

Table 3. Degree of trauma and odds ratios for symptoms of prolapse, urinary incontinence, anal incontinence, sexual function and other outcomes. ${ }^{\dagger}$ Cesarean section was compared to vaginal delivery. Data are OR $(95 \% \mathrm{CI}) \not$ Adjusted for age and fetal weight and BMI na = not analysed.

experiencing dyspareunia was elevated in women with OASI (OR 3.1, Table 3). The feeling of being too tight (14.6\%) was more common than the feeling of being too loose $(8.6 \%)$.

Perineal pain was experienced by $11.6 \%$ of women, and 21 women reported that pain that was severe enough to prevent most activities in the last 3 months. This type of severe pain was present in all groups, with an elevated risk in the OASI group (OR 3.3, Table 3). OASI was a risk factor for symptoms originating from the injury that had an impact on daily activities (OR 18, Table 3). Patients with OASI had the highest rate of complications.

\section{Discussion}

In this study, we evaluated pelvic floor function one year after birth in a nonselected cohort of primiparas and found that adverse functional outcomes were experienced in women with perineal lacerations of all grades as well as those with an intact perineum. Dyspareunia and urinary incontinence were the most common symptoms of pelvic floor dysfunction one year after childbirth. Those who suffered from OASI had a significantly higher risk of experiencing symptoms of prolapse, urinary urge incontinence, anal incontinence, dyspareunia and pain. Patients with OASI also had a significant risk of their injury impacting daily life one year after giving birth. Notably, women with moderate perineal lacerations (second-degree and episiotomy injuries) reported various symptoms of perineal dysfunction one year after delivery, and second-degree trauma was a risk factor for urinary stress incontinence.

Women who underwent cesarean section generally had a low incidence of dysfunction apart from dyspareunia (31\%), for which the prevalence was in line with that in women with an intact perineum. Cesarean section was also protective against stress incontinence. The results may have been affected by the fact that this was an allencompassing cesarean section group including women who underwent elective (35\%) and emergency cesarean sections; nevertheless, the prevalence of perineal dysfunction seemed to be lower in this group than in the other groups. Similar findings have been reported in evaluations of pelvic floor function 5 and 10 years after birth, in which cesarean section deliveries were associated with significantly lower hazards for stress urinary incontinence, overactive bladder, and pelvic organ prolapse ${ }^{8}$. However, birth by cesarean section is associated with a risk of pelvic floor morbidity coupled to the surgery itself?.

Pain during intercourse was reported in $38 \%$ of the women, which is in line with data from previous studies $(22.4-37.3 \%)^{6,10}$. The etiology of dyspareunia is multifactorial; scar formation after perineal laceration is one possible cause; other causes include inflammatory states, infections, and lack of sexual arousal ${ }^{11}$. The incidence of dyspareunia has been reported to increase after childbirth, from $12 \%$ before pregnancy to $31 \%$ six months after birth ${ }^{12}$. Breastfeeding has traditionally been used by midwives and gynecologists as an explanation for postpartum dyspareunia and was found to be a risk factor for dyspareunia at 6 months after birth in a recent study $^{13}$. In Sweden, more than $70 \%$ of mothers have ceased breastfeeding at 12 months after birth ${ }^{2}$. To obtain in-depth knowledge of sexual function after childbirth, one needs to assess prepregnancy function and perform repeated follow-ups with a validated assessment tool, such as the pelvic organ prolapse/incontinence sexual questionnaire-IUGA revised (PISQ-IR) ${ }^{14}$. 
In our study, the frequency of urinary incontinence was lowest in the subgroup who underwent cesarean section and was highest among patients with major injuries. Symptoms of prolapse were most prominent in patients with OASI. A previous study showed that vaginal delivery was associated with higher risks of prolapse and urinary incontinence than cesarean delivery ${ }^{15}$.

A similar trend was observed for anal incontinence. Excluding patients with OASI, severe anal incontinence with leakage of stool was found in only women with vaginal deliveries, which might indicate that they had undiagnosed sphincter injuries ${ }^{16,17}$. Various studies have postulated that the frequency of undiagnosed OASI is high, at $11-29 \%{ }^{16-18}$. Women with OASI reported a significant impact of symptoms on daily life. Other studies have also shown that anal incontinence results in a decrease in overall quality of life ${ }^{19}$.

We recognize that there are limitations to our study due to the inclusion of measurements of rather subtle pelvic floor dysfunction characterized by symptoms occurring as little as once a month. There were no objective measures, such as in-person examinations, during follow-up. On the other hand, functional impairment is an easy way to identify patients who need further evaluation and treatment. In the aftermath of childbirth-related trauma, early identification of pelvic floor dysfunction enables us to intervene with effective strategies (such as pelvic floor rehabilitation) to prevent subsequent aggravation of pelvic floor dysfunction requiring surgery. Predicting and preventing long-term morbidity due to injury to the pelvic floor will also decrease healthcare costs ${ }^{20}$.

There are a number of biases inherent to investigations utilizing questionnaires that we tried to minimize by using a shortened version of an already existing and validated national questionnaire ${ }^{21}$. One possible bias is that respondents experiencing symptoms were more likely to respond, but those experiencing symptoms were comparable to the nonrespondents in the majority of baseline characteristics. The responders were older than the nonresponders, representing a potential source of responder bias given that age is a risk factor for pelvic floor dysfunction, but responder bias is unlikely due to the minor differences. Confidence intervals were wide in the OASI group due to an OASI prevalence of $4.5 \%$, leading to a small sample size $(n=19)$.

The strengths of this study include its prospective cohort design and the nonselected study population since the hospital is the only one in the area. Higher fetal weight, a longer secondary active state and occiput posterior position are well-known risk factors for both $\mathrm{OASI}^{22}$ and levator trauma ${ }^{23}$. Patients who stated that they were pregnant at the time of the questionnaire were excluded from the analysis of symptoms to ensure that the results were not affected by the impact of pregnancy on function; consequently, the population eligible for analysis was substantially reduced.

The average rate of vacuum extraction in the country is $9.5 \%$; in this study, the prevalence was $11.1 \%$. Responders had a higher rate of vacuum delivery than nonresponders, creating possible bias due to more traumatic birth experiences. The episiotomy rate was markedly higher than the national average, at $20 \%$ in this study compared to $10 \%$ nationally ${ }^{2}$. On the other hand, vacuum delivery and episiotomy were not risk factors for pelvic floor dysfunction in this study. Vacuum extraction is associated with an increased prevalence of OASI and second-degree tears ${ }^{24}$. Episiotomy was more common in vacuum deliveries than in other types of deliveries, probably because clinical practice has been influenced by studies suggesting the reduced risk of OASI when performing episiotomy in vacuum deliveries in nulliparas ${ }^{25}$. The benefits and risks of routine episiotomy have been widely debated ${ }^{26}$. Recent studies have concluded that selective episiotomy is recommended when normal delivery is anticipated ${ }^{27,28}$. A reduction in the episiotomy rate in unassisted vaginal deliveries led to an increase in second-degree injuries of anatomic damage less than or equal to that caused by episiotomy without and increased rate of severe second-degree injuries ${ }^{28}$. There is continuing support for the use of episiotomy in vacuum delivery in nulliparas ${ }^{29}$ although the number needed to treat was 27 , and the results from randomized controlled trials to validate these recommendations are awaited ${ }^{30}$. Episiotomy is an obstetric technique associated with levator injury ${ }^{23}$. Trauma to the levator ani during vaginal childbirth is associated with female pelvic organ prolapse $^{31}$ and has been suggested but not confirmed to have an association with symptoms of urinary and anal incontinence ${ }^{32,33}$. Regarding sexual function, a recent study found no association between postpartum levator hiatus and sexual dysfunction ${ }^{34}$.

In conclusion, OASI is an evident risk factor for pelvic floor dysfunction after childbirth, but symptoms of pelvic floor disorder were found to be common, even in women with mild to moderate perineal laceration. Second-degree lacerations have a wide range of perineal tear extension and a subclassification may be helpful further to stratify the risk of subsequent pelvic floor dysfunction ${ }^{28}$. An elevated risk associated with a larger injury was observed in our study, and women with OASI reported a significant impact of their symptoms on daily life. This indicates that strategies should remain focused on preventative measures and improved diagnostics for large perineal lacerations.

Since pelvic floor disorders are stigmatizing conditions causing great physical and emotional suffering, measures aiming to reduce postpartum morbidity and to improve women's sexual health are of great importance. The association between perineal trauma and levator trauma ${ }^{35}$ and the increased risk of long-term pelvic dysfunction with composite trauma constitutes an important area for further research to increase confidence in vaginal births and mitigate the increased demand for cesarean sections.

\section{Methods}

This study was part of a large interdisciplinary project involving birth-related perineal injuries, endoanal ultrasonography and postpartum pelvic floor disorders. The present study is a follow-up study in the cohort of the aforementioned project. The project aimed to prospectively include all nulliparous women who gave birth from January 2016 to January 2018 at Östersund Hospital. This is the only hospital in the county of JämtlandHärjedalen, Sweden, and approximately $98 \%$ of pregnant women residing in the area give birth at this hospital. Written consent to participate in the study was obtained at the routine fetal anomaly scan at 18-20 weeks of pregnancy. 


\begin{tabular}{|l|l|}
\hline Degree of tear & Perineal injury \\
\hline 1 & Perineal skin and vaginal mucosa \\
\hline 2 & Beyond perineal skin into muscles of perineal body \\
\hline \multirow{3}{*}{3} & A. External anal sphincter (less than $50 \%)$ \\
\cline { 2 - 2 } & B. External anal sphincter (more than $50 \%)$ \\
\cline { 2 - 2 } & C. External and internal anal sphincter \\
\hline 4 & External and internal anal sphincter; anal mucosa \\
\hline
\end{tabular}

Table 4. World Health Organization (WHO) classification of perineal tears. Grades 3-4 are regarded as obstetric anal sphincter injury (OASI).

Women who agreed to participate in the study were clinically examined immediately after birth to diagnose perineal injury. The clinical examination was performed by a midwife or, in eligible cases, by a doctor, and consisted of inspection and bidigital palpation in the lithotomy position. The laceration grade was documented by the midwife or doctor according to the International Classification of Diseases Tenth Revision (ICD-10) World Health Organization (WHO) guidelines (Table 4). Only mediolateral episiotomy was performed. The findings were documented in a study protocol. Data on maternal, obstetric and neonatal characteristics were obtained from medical records.

Participants who were one year postpartum received an invitation to complete a follow-up questionnaire by mail. An information sheet that explained the purpose of the study, security standards, data storage, and the consent process and provided the contact information of the responsible investigators was included with the letter. Participants were asked to complete a web-based questionnaire regarding symptoms of prolapse, urinary incontinence, anal incontinence, and perineal pain as well as sexual function. The questionnaire consisted of 15 questions and contained the most important items of the questionnaire for the postoperative evaluation of perineal injury provided by the National Swedish Society of Obstetrics and Gynecology ${ }^{21}$. The scored items of the questionnaire were validated. The questionnaire was available in only Swedish (native language). All questions had "no" or "never" as response options, and for questions about sexual function, patients had the option of not answering without being excluded from the analysis. Adaptive questioning processes were used in cases where supplementary questions were required to obtain further details on occurring symptoms, such as anal incontinence. Completion of the survey was voluntary. The patients provided informed consent by logging in with their individual codes and submitting the results. Participants received two reminders by text message and/ or telephone call. Answers were automatically recorded in a database to which only the responsible investigators had access.

The participants were divided into three groups depending on the extent of perineal injury (no/first-degree injury, second-degree injury, and OASI). Women who underwent cesarean section comprised the fourth group. The period prevalence of self-reported symptoms of prolapse, urinary and fecal incontinence, dyspareunia and perineal pain were calculated based on the proportion of women who reported symptoms that matched the study definitions divided by the total number of women with available data for follow-up. In cases of multiple birth, the study considered the infant with the highest birthweight. Prolapse was defined as the feeling of something bulging out of the vagina or the need to press against the posterior vaginal wall to empty the bowel once a month or more. Stress urinary incontinence was defined as incontinence once a week to daily, urge incontinence as once a month to daily. Impact on daily activity was defined as noticeable symptoms once a month or more often. Involuntary passing of flatus was defined as the involuntary passing flatus once a month or more. Leakage of stool was defined as stool leakage once a month to daily. Sexually active was defined as intercourse within the last three months. Perineal pain was defined as pain that is impossible to ignore and that affects concentration on daily tasks and activities. The statement "very satisfied" or "satisfied" was used to determine satisfaction with suturing.

Statistical analyses were performed by analysis of variance for continuous data (ANOVA). The chi-square test or Fisher's exact test was used as needed for categorical data, and the independent-sample t test was used for normally distributed continuous data. When analysis with the chi-square test was performed with more than two groups and statistical significance was found, pairwise testing and post hoc testing was performed to verify the finding. Odds ratios were calculated with binary logistic regression analysis, with $95 \%$ confidence intervals (CIs). Odds ratios were adjusted for age, body mass index (BMI) and fetal weight when appropriate. After ANOVA analysis, the posthoc test was performed to identify the groups that demonstrate statistically significant differences. Patients with no/first-degree injuries were compared with patients with second-degree injuries and OASI, as well as with participants who gave birth by cesarean section. Significance was set at $\mathrm{p}<0.05$. Analysis of power was performed in the initial study of the project; because the current study is a follow-up study involving the same cohort, power analysis was not applicable. All the data were compiled in an encoded database using Microsoft Access for Office 365, Version 1908 (Microsoft Corp., Redmond, WA, USA). Analyses were performed using SPSS Version 24 (IBM SPSS Statistics, Armonk, NY).

Ethical approval was granted by the Regional Ethical Review Board of Umeå (Nr. 2016-458-31 M). Informed consent was obtained from all participants. All data were deidentified prior to analysis. All experiments were performed in accordance with relevant guidelines and regulations. Patients could choose at any stage of the study to terminate their participation. 


\section{Data availability}

The datasets generated and/or analyzed during the current study are not publicly available due to their containing information that could compromise the privacy of research participants but are available from the corresponding author upon reasonable request.

Received: 29 July 2020; Accepted: 26 May 2021

Published online: 15 June 2021

\section{References}

1. Thiagamoorthy, G., Johnson, A., Thakar, R. \& Sultan, A. H. National survey of perineal trauma and its subsequent management in the United Kingdom. Int. Urogynecol. J. 25, 1621-1627. https://doi.org/10.1007/s00192-014-2406-x (2014).

2. The Swedish Pregnancy Registry (2016-2018).

3. Gyhagen, M., Akervall, S. \& Milsom, I. Clustering of pelvic floor disorders 20 years after one vaginal or one cesarean birth. Int. Urogynecol. J. 26, 1115-1121. https://doi.org/10.1007/s00192-015-2663-3 (2015).

4. Volloyhaug, I., Morkved, S. \& Salvesen, K. A. Association between pelvic floor muscle trauma and pelvic organ prolapse 20 years after delivery. Int. Urogynecol. J. 27, 39-45. https://doi.org/10.1007/s00192-015-2784-8 (2016).

5. Gartland, D., MacArthur, C., Woolhouse, H., McDonald, E. \& Brown, S. J. Frequency, severity and risk factors for urinary and faecal incontinence at 4 years postpartum: A prospective cohort. BJOG 123, 1203-1211. https://doi.org/10.1111/1471-0528.13522 (2016).

6. Signorello, L. B., Harlow, B. L., Chekos, A. K. \& Repke, J. T. Postpartum sexual functioning and its relationship to perineal trauma: A retrospective cohort study of primiparous women. Am. J. Obstet. Gynecol. 184, 881-888. https://doi.org/10.1067/mob.2001. 113855 (2001) (discussion 888-890).

7. Walsh, K. A. \& Grivell, R. M. Use of endoanal ultrasound for reducing the risk of complications related to anal sphincter injury after vaginal birth. Cochrane Database Syst. Rev. 10, CD010826. https://doi.org/10.1002/14651858.CD010826.pub2 (2015).

8. Blomquist, J. L., Munoz, A., Carroll, M. \& Handa, V. L. Association of delivery mode with pelvic floor disorders after childbirth. JAMA 320, 2438-2447. https://doi.org/10.1001/jama.2018.18315 (2018).

9. Franchi, M. et al. Unintentional transvesical caesarean section: Incidence, risk factors, surgical technique and post-operative management. Eur. J. Obstet. Gynecol. Reprod. Biol. 236, 26-31. https://doi.org/10.1016/j.ejogrb.2019.02.023 (2019).

10. Lipschuetz, M. et al. Degree of bother from pelvic floor dysfunction in women one year after first delivery. Eur. J. Obstet. Gynecol. Reprod. Biol. 191, 90-94. https://doi.org/10.1016/j.ejogrb.2015.05.015 (2015).

11. Lee, N. M. W., Jakes, A. D., Lloyd, J. \& Frodsham, L. C. G. Dyspareunia. BMJ 361, k2341. https://doi.org/10.1136/bmj.k2341 (2018).

12. Barrett, G. et al. Women's sexual health after childbirth. BJOG 107, 186-195. https://doi.org/10.1111/j.1471-0528.2000.tb11689.x (2000).

13. Alligood-Percoco, N. R., Kjerulff, K. H. \& Repke, J. T. Risk factors for dyspareunia after first childbirth. Obstet. Gynecol. 128, 512-518. https://doi.org/10.1097/AOG.0000000000001590 (2016).

14. Rogers, R. G. \& Pons, M. E. E. The pelvic organ prolapse incontinence sexual questionnaire, IUGA-revised (PISQ-IR). Int. Urogynecol. J. 24, 1063-1064. https://doi.org/10.1007/s00192-012-1952-3 (2013).

15. Handa, V. L. et al. Pelvic floor disorders 5-10 years after vaginal or cesarean childbirth. Obstet. Gynecol. 118, 777-784. https://doi. org/10.1097/AOG.0b013e3182267f2f (2011).

16. Williams, A. B. et al. Anal sphincter damage after vaginal delivery using three-dimensional endosonography. Obstet. Gynecol. 97, $770-775$ (2001).

17. Rojas, R. A. G., Shek, K. L., Langer, S. M. \& Dietz, H. P. Prevalence of anal sphincter injury in primiparous women. Ultrasound Obstet. Gynecol. 42, 461-466. https://doi.org/10.1002/uog.12481 (2013).

18. Andrews, V., Sultan, A. H., Thakar, R. \& Jones, P. W. Occult anal sphincter injuries-myth or reality?. BJOG 113, 195-200. https:// doi.org/10.1111/j.1471-0528.2006.00799.x (2006).

19. Sharma, A. et al. Determining levels of fecal incontinence in the community: A New Zealand cross-sectional study. Dis. Colon Rectum 54, 1381-1387. https://doi.org/10.1097/DCR.0b013e31822dd0f0 (2011).

20. Deutekom, M. et al. Costs of outpatients with fecal incontinence. Scand. J. Gastroenterol. 40, 552-558. https://doi.org/10.1080/ $00365520510012172(2005)$.

21. Gyn, O. P. Gyn op registret Bristningsregistret, http://www.gynop.org/webhelp/gynopnet/gynopnet.htm.

22. Jango, H., Langhoff-Roos, J., Rosthoj, S. \& Sakse, A. Modifiable risk factors of obstetric anal sphincter injury in primiparous women: A population-based cohort study. Am. J. Obstet. Gynecol. 210(59), e51-56. https://doi.org/10.1016/j.ajog.2013.08.043 (2014).

23. Shek, K. L. \& Dietz, H. P. Intrapartum risk factors for levator trauma. BJOG 117, 1485-1492. https://doi.org/10.1111/j.1471-0528. 2010.02704.x (2010).

24. Jansson, M. H. et al. Risk factors for perineal and vaginal tears in primiparous women: The prospective POPRACT-cohort study. BMC Pregnancy Childbirth 20, 749. https://doi.org/10.1186/s12884-020-03447-0 (2020).

25. Raisanen, S., Vehvilainen-Julkunen, K., Gissler, M. \& Heinonen, S. High episiotomy rate protects from obstetric anal sphincter ruptures: A birth register-study on delivery intervention policies in Finland. Scand. J. Public Health 39, 457-463. https://doi.org/ $10.1177 / 1403494811404276(2011)$.

26. Blondel, B. et al. Variations in rates of severe perineal tears and episiotomies in 20 European countries: A study based on routine national data in Euro-Peristat Project. Acta Obstet. Gynecol. Scand. 95, 746-754. https://doi.org/10.1111/aogs.12894 (2016).

27. Jiang, H., Qian, X., Carroli, G. \& Garner, P. Selective versus routine use of episiotomy for vaginal birth. Cochrane Database Syst. Rev. 2, CD000081. https://doi.org/10.1002/14651858.CD000081.pub3 (2017).

28. Franchi, M. et al. Selective use of episiotomy: What is the impact on perineal trauma? Results from a retrospective cohort study. Arch. Gynecol. Obstet. 301, 427-435. https://doi.org/10.1007/s00404-019-05404-5 (2020).

29. Ankarcrona, V., Zhao, H., Jacobsson, B. \& Brismar Wendel, S. Obstetric anal sphincter injury after episiotomy in vacuum extraction: An epidemiological study using an emulated randomized trial approach. BJOG https://doi.org/10.1111/1471-0528.16663 (2021).

30. Bergendahl, S. et al. Lateral episiotomy versus no episiotomy to reduce obstetric anal sphincter injury in vacuum-assisted delivery in nulliparous women: Study protocol on a randomised controlled trial. BMJ Open 9, e025050. https://doi.org/10.1136/bmjop en-2018-025050 (2019).

31. DeLancey, J. O. et al. Comparison of levator ani muscle defects and function in women with and without pelvic organ prolapse. Obstet. Gynecol. 109, 295-302. https://doi.org/10.1097/01.AOG.0000250901.57095.ba (2007).

32. Mathew, S., Guzman Rojas, R. A., Salvesen, K. A. \& Volloyhaug, I. Levator ani muscle injury and risk for urinary and fecal incontinence in parous women from a normal population, a cross-sectional study. Neurourol. Urodyn. 38, 2296-2302. https://doi.org/ $10.1002 /$ nau. 24138 (2019).

33. Volloyhaug, I., Taithongchai, A., Van Gruting, I., Sultan, A. \& Thakar, R. Levator ani muscle morphology and function in women with obstetric anal sphincter injury. Ultrasound Obstet. Gynecol. 53, 410-416. https://doi.org/10.1002/uog.20115 (2019).

34. Roos, A. M., Speksnijder, L. \& Steensma, A. B. Postpartum sexual function; the importance of the levator ani muscle. Int. Urogynecol. J. https://doi.org/10.1007/s00192-020-04250-3 (2020). 
35. Shek, K. L., Green, K., Hall, J., Guzman-Rojas, R. \& Dietz, H. P. Perineal and vaginal tears are clinical markers for occult levator ani trauma: A retrospective observational study. Ultrasound Obstet. Gynecol. 47, 224-227. https://doi.org/10.1002/uog.14856 (2016).

\section{Acknowledgements}

We would like to thank Lars Söderström for his contribution to the statistical analysis, Ulla Jämting for her help in administering the questionnaire, and Fredrik Bornhov for assistance in collecting data.

\section{Author contributions}

M.H. and K.T. designed the study. M.H. recruited the participants. Huber conducted data collection. M.H. and E.M. analyzed and interpreted the data, and all authors were involved in refining the analysis. M.H. and E.M. prepared the manuscript, and all authors edited the manuscript. All authors have read and approved the final manuscript and agree with its submission to Scientific Reports.

\section{Funding}

Open access funding provided by Umea University. This study was funded by grants from the Unit of Research, Education and Development, Region Jämtland-Härjedalen, and VisareNorr, Northern County Councils, Sweden.

\section{Competing interests}

The authors declare no competing interests.

\section{Additional information}

Correspondence and requests for materials should be addressed to M.H.

Reprints and permissions information is available at www.nature.com/reprints.

Publisher's note Springer Nature remains neutral with regard to jurisdictional claims in published maps and institutional affiliations.

(c) (i) Open Access This article is licensed under a Creative Commons Attribution 4.0 International License, which permits use, sharing, adaptation, distribution and reproduction in any medium or format, as long as you give appropriate credit to the original author(s) and the source, provide a link to the Creative Commons licence, and indicate if changes were made. The images or other third party material in this article are included in the article's Creative Commons licence, unless indicated otherwise in a credit line to the material. If material is not included in the article's Creative Commons licence and your intended use is not permitted by statutory regulation or exceeds the permitted use, you will need to obtain permission directly from the copyright holder. To view a copy of this licence, visit http://creativecommons.org/licenses/by/4.0/.

(C) The Author(s) 2021 